\title{
Colegiados de Gestão Regional no estado do Rio de Janeiro: atores, estratégias e negociação intergovernamental
}

| ${ }^{1}$ Renata Pestana Vianna, ${ }^{2}$ Luciana Dias de Lima |

Resumo: O estudo analisou a conformação dos Colegiados de Gestão Regional (CGRs) no estado do Rio de Janeiro, no contexto do Pacto pela Saúde, a partir de quatro dimensões principais: indução e implantação inicial, institucionalidade, processo político e padrões de relacionamento (intergovernamental e entre organismos de gestão compartilhada) e capacidade de atuação dos CGRs. Foram identificados os principais atores envolvidos e as estratégias utilizadas no processo de implantação, bem como a dinâmica de funcionamento e o conteúdo das negociações nessas instâncias regionais. A implantação dos CGRs no Rio de Janeiro ocorreu tardiamente se comparado a outros estados do Brasil, acompanhando, no entanto, o padrão de desenvolvimento das políticas de regionalização no estado. Percebeu-se que o funcionamento dessas instâncias de negociação e pactuação intergovernamental apresentou variações entre as regiōes, relacionadas, principalmente, à preexistência de práticas de planejamento, estruturas e mecanismos de cogestão regional. Em relação às potencialidades e desafios dos CGRs, observou-se que, embora constituídas recentemente, essas instâncias lograram promover maior integração entre os entes governamentais nos espaços regionais. Além disso, favoreceram a troca de experiência e o aprendizado entre os gestores, particularmente em relação às políticas públicas de saúde. No entanto, o trabalho empírico sugere que ainda é preciso avançar no que diz respeito ao desenvolvimento de uma cultura de planejamento regional, que possibilite maior autonomia das regiōes no desenvolvimento de políticas ajustadas a suas próprias realidades. Nesse processo, a função indutora e coordenadora atribuída à esfera estadual será de extrema importância.

\author{
${ }^{1}$ Mestre em Saúde Pública, \\ subárea de Planejamento e \\ Gestão de Serviços e Sistema \\ de Saúde pela Escola Nacional \\ de Saúde Pública Sérgio \\ Arouca/Fiocruz, Rio de Janeiro, \\ Brasil. Endereço eletrônico: \\ renataviannarj@gmail.com \\ ${ }^{2}$ Bolsista produtividade \\ do CNPq; pesquisadora \\ titular do Departamento de \\ Administração e Planejamento \\ em Saúde, docente permanente \\ do Programa de Pós-Graduação \\ em Saúde Pública, ENSP/ \\ Fiocruz, Rio de Janeiro, Brasil. \\ Endereço eletrônico: Iuciana@ \\ ensp.fiocruz.br
}


O Sistema Único de Saúde (SUS), desde o início de sua implantação, conta com o funcionamento de instâncias de pactuação federativa, que se fizeram necessárias para propiciar a negociação entre as diferentes esferas de governo no processo de formulação e implementação da política de saúde (NORONHA; LIMA; MACHADO, 2012). Tais instâncias foram instituídas ainda na década de 1990, em âmbito nacional e estadual, sob a denominação de Comissão Intergestores Tripartite (CIT) e Comissões Intergestores Bipartite (CIB).

A CIT iniciou seu funcionamento em 1991 e se consolidou como espaço de debate sobre temas relevantes da política nacional de saúde, traduzidos na normatização e nos diversos mecanismos de transferência de recursos federais do SUS (LEVCOVITZ; LIMA; MACHADO, 2001). Já as CIBs foram implantadas a partir de 1993, e permitiram a adequação das normas nacionais às condições específicas de cada estado, por meio de medidas reguladoras das relaçôes intergovernamentais na gestão e distribuição de recursos financeiros do SUS (LUCCHESE, 1996).

Em que pese o caráter especializado e restrito dessas instâncias, estudos sugerem resultados positivos em relação aos processos decisórios nas CIBs. Entre eles, a possibilidade da representação de diferentes grupos de interesse, a construção da parceria entre estado e municípios, e a consolidação de uma prática de negociação entre os gestores mais equilibrada, democrática e participativa (RIBEIRO, 1997; LIMA, 1999; SILVA; LABRA, 2001).

Com uma visão mais crítica, Miranda (2010) ressalta a influência dos acordos estabelecidos em nível federal no funcionamento das CIBs, que acaba por conferir um caráter de "governabilidade resiliente" às negociações intergovernamentais nos estados.

Destaca-se que as comissões intergestores atuaram em consonância com o contexto político no qual se inseriram e com os papéis a elas atribuídos na política de saúde (MACHADO; VIANA, 2009; LIMA; VIANA, 2011). Nos anos 90, a descentralização foi a temática predominante e, na década de 2000, a regionalização do sistema de saúde ganhou relevo nas pautas da CIT e das CIBs. Em 2006, com o lançamento do Pacto pela Saúde, novas diretrizes foram preconizadas para apoiar a regionalização. O caráter político desse processo 
foi enfatizado, subordinando-se a configuração das regiōes de saúde no plano estadual à pactuação entre os entes federados (VIANA et al., 2008).

A concepção política da regionalização traduz-se na proposição de um novo espaço de negociação intergovernamental: os Colegiados de Gestão Regional (CGRs). Estes se configuram como organizações permanentes e com regras próprias, formadas pela representação do estado e do conjunto de municípios nas regiōes expressas nos Planos de Regionalização (BRASIL, 2009). Ainda que em alguns estados fosse possível identificar mecanismos de articulação entre os governos em âmbito regional, conformados na segunda metade dos anos 90, tais como as CIBs Regionais e os Consórcios, essas experiências não se configuraram como estratégia disseminada no território brasileiro (SCHNEIDER, 2001; LIMA, 2000; QUEIROZ, 2001).

Tendo sido formalizada como política nacional, a conformação dos CGRs renova a possibilidade de considerar as especificidades das regiôes no processo de planejamento, através da identificação de problemas e prioridades, e proposição de alternativas mais adequadas às realidades regionais. A potencialidade dessas instâncias em fortalecer o enfoque territorial no planejamento em saúde, com incorporação de diferentes atores políticos pertencentes às regiões, sugere o espaço regional como lócus de formulação e implementação de políticas.

Os Colegiados de Gestão Regional foram instituídos gradativamente no Brasil. Pesquisas sugerem que sua implantação no território nacional não ocorreu de forma homogênea, dada à variedade de contextos e dos fenômenos que influenciam as experiências estaduais (VIANA; LIMA; FERREIRA, 2010; LIMA et al., 2012). Nesse sentido, estudos de caso sobre a conformação dos CGRs podem contribuir para compreensão das especificidades estaduais e regionais que condicionam esse processo.

Mas de que forma os CGRs são capazes de ocupar esse espaço regional pouco valorizado em políticas anteriores? Como tem se dado o funcionamento dos CGRs? Em que medida os CGRs podem contribuir para o fortalecimento do processo de planejamento e cogestão regional? Que fatores favorecem ou dificultam o processo de regionalização e a implementação dos CGRs? Tais questões orientaram a pesquisa apresentada neste artigo, que teve como foco a análise da implantação dos Colegiados de Gestão Regional no estado do Rio de Janeiro, valorizando-se seus condicionantes, os atores envolvidos e as 
estratégias utilizadas nesse processo. Buscou-se, ainda, caracterizar a dinâmica de funcionamento e o conteúdo das negociações presentes nos CGRs.

\section{Metodologia}

O trabalho consistiu em um estudo de caso da implantação dos Colegiados de Gestão Regional no estado do Rio de Janeiro, em que se buscou preservar elementos do contexto e identificar fatores explicativos do processo social em questão em uma situação particular (YIN, 2001). A escolha do Rio de Janeiro foi motivada pela singularidade do território fluminense, que expressa, entre outros legados históricos, importante concentração populacional na região metropolitana, o sentido de "capitalidade" atrelado às mudanças jurídico-administrativas da cidade do RJ - capital federal (1889-1960), estado da Guanabara (1960-1975) e capital do estado (1975 até os dias atuais) - e as desigualdades e dificuldades de integração regional no estado (DAVIDOVICH, 2000; LESSA, 2005; NATAL, 2005). Do ponto de vista das políticas públicas, destacam-se os conflitos federativos, o insulamento e dependência da capital na conformação da rede regionalizada de serviços de saúde (PARADA, 2001; GERSCHMAN, 2010)

A pesquisa ancorou-se no referencial de análise de políticas públicas (HAM; HILL, 1993) e, particularmente, na abordagem do ciclo da política (HOWLET; RAMESH, 1995), priorizando os condicionantes, os atores envolvidos e as estratégias adotadas no processo de implantação dos CGRs. A análise também incorporou as contribuiçôes do institucionalismo histórico (HALL; TAYLOR, 2003; THELEN; STEINMO, 1992), no que se refere à compreensão do modo como práticas de planejamento regional e arranjos institucionais previamente instituídos influenciaram as escolhas políticas dos agentes governamentais e o modo de operação dos CGRs nas regiōes.

A pesquisa empírica, de natureza eminentemente qualitativa, privilegiou o período de 2007 a 2011. Adotaram-se como principais estratégias metodológicas a análise documental e entrevistas com dirigentes estaduais e municipais. Os documentos selecionados incluíram a legislação e normatizações federais e estaduais referentes à regionalização e à atuação dos CGRs, planos e instrumentos de programação (Plano Estadual de Saúde, Plano Diretor de Regionalização, 
Plano Diretor de Investimentos, Programação Pactuada e Integrada), Regimento

Interno e atas dos Colegiados e da CIB.

As entrevistas foram realizadas com atores-chave da política de regionalização da saúde no estado, incluindo os Coordenadores dos CGRs. Foram utilizados dois tipos de instrumentos: um roteiro semiestruturado e outro estruturado (questionário com algumas questões abertas). Realizaram-se oito entrevistas semiestruturadas; quatro com os responsáveis pela regionalização da Secretaria Estadual de Saúde (SES) e quatro com secretários municipais de Saúde integrantes da Diretoria do Conselho de Secretarias Municipais de Saúde do Rio de Janeiro (COSEMS). As entrevistas estruturadas, gravadas e posteriormente transcritas, direcionaram-se aos coordenadores dos colegiados em cada região, totalizando dez entrevistas. Todos os coordenadores regionais eram funcionários da SES, apresentando vínculos e trajetórias profissionais diversas no estado. Em todas as entrevistas realizadas estabeleceu-se uma codificação específica dos entrevistados para garantia do anonimato na apresentação dos resultados.

O processo de implantação dos colegiados foi apreendido com base em quatro dimensões principais, que serviram como referência para construção dos instrumentos, agregação e análise do material empírico: indução e implantação inicial; institucionalidade; processo político e padrões de relacionamento; capacidade de atuação dos CGRs (quadro 1).

\section{Quadro 1}

\begin{tabular}{|l|l|l|}
\hline \multicolumn{1}{|c|}{ Dimensões } & \multicolumn{1}{c|}{\begin{tabular}{c}
\multicolumn{1}{c|}{ Subdimensões } \\
O CGR na agenda \\
governamental
\end{tabular}} & $\begin{array}{l}\text { Variáveis } \\
\text {-Fatores que influenciaram a introdução da temática na } \\
\text { agenda estadual e municipal. } \\
\text {-Prioridade da temática na agenda }\end{array}$ \\
\cline { 2 - 3 } $\begin{array}{l}\text { Indução e } \\
\text { Implantação Inicial } \\
\text { do CGR }\end{array}$ & Atores envolvidos & $\begin{array}{l}\text {-Papel da Secretaria Estadual de Saúde, Conselho } \\
\text { Comissão Intergestores Bipartite (CIB) e Conselho } \\
\text { Estadual de Saúde (CES) no processo de implementação } \\
\text { do CGR }\end{array}$ \\
\cline { 2 - 3 } & $\begin{array}{l}\text { Estratégias } \\
\text { e incentivos } \\
\text { utilizados para a } \\
\text { implementação }\end{array}$ & $\begin{array}{l}\text {-Tipos de incentivos e estratégias para indução da } \\
\text { implantação (financeiro, profissional...) }\end{array}$ \\
\hline
\end{tabular}




\begin{tabular}{|c|c|c|}
\hline Dimensóes & Subdimensóes & Variáveis \\
\hline \multirow{3}{*}{$\begin{array}{l}\text { Institucionalidade } \\
\text { do CGR }\end{array}$} & $\begin{array}{l}\text { Histórico da } \\
\text { Regionalização }\end{array}$ & $\begin{array}{l}\text {-Existência de estruturas regionais constituídas } \\
\text { previamente ao Pacto pela Saúde } \\
\text {-Práticas pré-existentes de planejamento e negociações } \\
\text { regionais }\end{array}$ \\
\hline & $\begin{array}{l}\text { Organização e } \\
\text { Funcionamento do } \\
\text { CGR }\end{array}$ & $\begin{array}{l}\text { - Tempo e tipos de instrumentos legais ou normativos de } \\
\text { implantação do CGR no estado } \\
\text {-Número, periodicidade e regularidade das reuniōes } \\
\text {-Existência e papel da Secretaria Executiva e do } \\
\text { coordenador do CGR } \\
\text { - Presença e atuação de estruturas técnico-políticas (ex: } \\
\text { Câmara técnica e Grupos de Trabalho) } \\
\text {-Existência e data da última atualização do Regimento } \\
\text { Interno } \\
\text { - Existência de uma agenda regular de reuniōes } \\
\text { _Existência de sede própria do CGR (espaço físico para } \\
\text { as reuniōes) e tipos de recursos disponíveis (financeiros, } \\
\text { materiais e humanos) }\end{array}$ \\
\hline & $\begin{array}{l}\text { Adequação e } \\
\text { Representatividade } \\
\text { Regional do CGR }\end{array}$ & $\begin{array}{l}\text {-Critérios utilizados para definição da abrangência e } \\
\text { recorte regional do CGR (condições socioeconômicas, } \\
\text { perfil do sistema de saúde, identidades culturais, fluxos } \\
\text { assistenciais, área de influência de cidades, infraestrutura } \\
\text { viária e de serviços) } \\
\text {-Perfil dos integrantes dos CGRs } \\
\text {-Rotatividade dos integrantes do CGR } \\
\text {-Existência de quórum para realização das reuniões } \\
\text { - Regularidade da participação dos gestores municipais de } \\
\text { saúde e do representante estadual de saúde } \\
\text {-Modos e critérios para a escolha do representante } \\
\text { estadual, Coordenador e/ou Secretário Executivo do } \\
\text { CGR } \\
\text {-Participação de outros atores de importância para a } \\
\text { região, como prestadores de serviços públicos ou privados } \\
\text { e organizaçôes colegiadas }\end{array}$ \\
\hline
\end{tabular}




\begin{tabular}{|c|c|c|}
\hline Dimensôes & Subdimensões & Variáveis \\
\hline \multirow{4}{*}{$\begin{array}{l}\text { Processo político } \\
\text { e padróes de } \\
\text { relacionamento do } \\
\text { CGR }\end{array}$} & $\begin{array}{l}\text { Principais } \\
\text { influências na } \\
\text { definição da pauta }\end{array}$ & $\begin{array}{l}\text { - Formas de definição da pauta (quem define a pauta; } \\
\text { critérios utilizados e principais influência na definição } \\
\text { da pauta) }\end{array}$ \\
\hline & $\begin{array}{l}\text { Temática } \\
\text { predominante }\end{array}$ & -Principais temas abordados \\
\hline & $\begin{array}{l}\text { Natureza e } \\
\text { tipos de relações } \\
\text { intergovernamentais } \\
\text { no CGR }\end{array}$ & $\begin{array}{l}\text { - Tipos de relaçóes entre os membros do CGR (técnico- } \\
\text { políticas, político-partidárias, pessoais, corporativas) } \\
\text {-Principais motivos de conflito entre os municípios } \\
\text { (divergências políticas, econômico-financeiro, técnicas, } \\
\text { etc.) } \\
\text { - Principais temas de consenso }\end{array}$ \\
\hline & $\begin{array}{l}\text { Relações do } \\
\text { CGR com outras } \\
\text { instâncias colegiadas } \\
\text { e de gestão regional }\end{array}$ & $\begin{array}{l}\text {-Existência, regularidade e tipos de relações estabelecidas } \\
\text { entre o CGR e as instâncias colegiadas (Consórcios, CIB, } \\
\text { COSEMS e Conselhos de Saúde) } \\
\text {-Existência, regularidade e tipos de relaçõos estabelecidas } \\
\text { entre o CGR e estruturas de gestão regional da SES } \\
\text {-Existência de estratégias de articulação, sobreposição ou } \\
\text { complementaridade de funçốes, conflitos e convergência }\end{array}$ \\
\hline \multirow[b]{2}{*}{$\begin{array}{l}\text { Capacidade de } \\
\text { atuação do CGR }\end{array}$} & $\begin{array}{l}\text { Planejamento } \\
\text { regional }\end{array}$ & $\begin{array}{l}\text {-Existência de um enfoque regional no diagnóstico e } \\
\text { elaboração de propostas } \\
\text { - Definição de prioridades e metas para a região } \\
\text {-Definição das responsabilidades de cada ente na região }\end{array}$ \\
\hline & $\begin{array}{l}\text { Gestão } \\
\text { Intergovernamental }\end{array}$ & $\begin{array}{l}\text {-Atualização e acompanhamento da PPI na região } \\
\text {-Existência de estratégias e instrumentos de regulação da } \\
\text { atenção à saúde em âmbito regional } \\
\text {-Existência de estratégias e instrumentos de } \\
\text { financiamento em âmbito regional } \\
\text {-Existência de estratégias e instrumentos para } \\
\text { formalização e monitoramento dos acordos } \\
\text { intergovernamentais }\end{array}$ \\
\hline
\end{tabular}

Fonte: Elaboração própria. 
Para análise dos documentos e, particularmente, das entrevistas semiestruturadas, foram aplicados os procedimentos de decomposição e distribuição temática e realizadas interpretaçōes baseadas no referencial teórico da pesquisa (BARDIN, 2010). Procurou-se identificar os elementos mais recorrentes e relevantes a partir da visão dos representantes da SES e do COSEMS, bem como a existência de convergências e divergências entre os entrevistados.

No que tange aos questionários, foi construído um banco de dados por meio do software SPSS (Statistical Package for the Social Sciences) e realizada análise descritiva simples das informações agregadas, a partir das quais elaboraram-se tabelas e gráficos. As informaçóes obtidas por meio dos questionários expressaram a visão dos coordenadores regionais. Tal estratégia configurou-se, neste estudo, como mais uma opção metodológica para apreensão do evento qualitativo em questão: o processo de implantação dos CGRs. Ressalta-se que as interpretações apresentadas no artigo resultam da adoção de uma perspectiva crítico-reflexiva dos autores sobre o conjunto do material empírico (documentos e entrevistas), considerando o referencial teórico e analítico do estudo (MINAYO, 2006).

O projeto de pesquisa foi aprovado pelo Comitê de Ética em Pesquisa da organização acadêmica envolvida no estudo, conforme os princípios legais e éticos da Resolução no 196/96 do Conselho Nacional de Saúde. Todos os entrevistados assinaram um Termo de Consentimento Livre e Esclarecido, cujo conteúdo assegurava-lhes o direito de recusa de participação e de sigilo das informaçôes fornecidas.

\section{Resultados}

\section{Indução e implantação inicial dos CGRs}

Os CGRs foram instituídos oficialmente em maio de 2009 (RIO DE JANEIRO, 2009a). Entretanto, é possível verificar a existência de iniciativas institucionais, motivos e interesses que antecederam e favoreceram a implantação dos CGRs no estado do Rio de Janeiro. Dentre essas iniciativas, destaca-se, ainda na década de 1990, a conformação de estruturas regionais, como as vice-presidências regionais do COSEMS e os consórcios de saúde e, nos anos 2000, as Centrais Estaduais Regionais de Regulação e os Núcleos Descentralizados de Vigilância em Saúde (NDVS). As duas primeiras experiências se deram, principalmente, por iniciativa própria dos municípios, enquanto as demais foram direcionadas pela SES, com 
vistas a desenvolver práticas regionalizadas nas áreas de vigilância à saúde e regulação.

Outros fatores também contribuíram para que a regionalização ocupasse papel de destaque nas políticas de saúde desenvolvidas no estado a partir de 2006. Entre esses, a ênfase na negociação regional e os incentivos à regionalização presentes nas políticas federais, e a necessidade de articulação das estruturas preexistentes e das ações em curso no Rio de Janeiro.

Observou-se que as diretrizes e instrumentos propostos no Pacto pela Saúde informaram o planejamento estadual de saúde no período de 2008 a 2011. O estado do Rio de Janeiro aderiu ao pacto no segundo semestre de 2007, assumindo uma série de atribuições e responsabilidades sanitárias relacionados ao Pacto de Gestão e pela Vida, que foram incorporadas no Plano Estadual de Saúde (RIO DE JANEIRO, 2008). Ressalta-se que o plano explicita como uma de suas diretrizes estratégicas a redefinição da política de regionalização, envolvendo a implantação dos CGRs em todas as regiōes. Do mesmo modo, outras políticas federais vigentes no período fomentaram a pactuação intergovernamental nas regiōes, como um pré-requisito para sua implantação e transferência de recursos financeiros. Alguns exemplos são a Política Nacional de Atenção às Urgências (BRASIL, 2003) e a Política Nacional de Educação Permanente (BRASIL, 2007).

No âmbito regional, duas questôes contribuíram para a adesão dos governos municipais à proposta de implantação dos CGRs. Uma primeira questão se refere às dificuldades para organizar um sistema de saúde integral nos limites administrativos da gestão local, problema que se agrava nos municípios de pequeno porte populacional. Tal limitação é ilustrada através da fala de um dos representantes do COSEMS:

Um dos principais dilemas de uma Secretaria Municipal de Saúde é ampliar o acesso aos serviços e garantir a integralidade das ações. Então, o CGR fortalece o diálogo entre os municípios e ajuda na construção de um sistema de saúde além dos limites do território municipal, facilitando o acesso das populações às ações e serviços de saúde.

Outra questão diz respeito às expectativas dos gestores municipais com relação à participação regular de um representante estadual nas reuniōes dos CGRs. $\mathrm{Na}$ visão dos representantes do COSEMS, a presença do estado poderia contribuir para o fortalecimento das negociações intergovernamentais em âmbito regional.

A atuação dos dirigentes do nível central da Secretaria de Estado de Saúde, por 
meio das estratégias e incentivos empregados, foi considerada pelos coordenadores regionais como fundamental para o processo de implantação dos CGRs (gráfico 1). Em 2007, a SES criou um programa denominado "Saúde na Área", cujo objetivo principal era aprofundar o conhecimento sobre a realidade municipal no estado. Como parte desse programa, por meio de parceria estabelecida com o COSEMS, realizaram-se em 2009 oficinas regionais cujos objetivos envolviam a elaboração de um diagnóstico situacional de saúde, avaliação da adequação do desenho das regiōes e a construção de uma agenda voltada para a revisão do Plano Diretor de Regionalização.

\section{Gráfico 1. Atores que participaram do processo de implantação dos CGRs nas regiôes segundo percepção dos Coordenadores Regionais - Rio de Janeiro, 2011}

Membros das instituições de ensino/pesquisa

Outros setores do governo estadual

Outras organizações dos municípios

Consórcio de saúde

Representante dos Conselhos de Saúde

Representante do COSEMS

Representante da SES

$\begin{array}{lllllllllll}0 & 1 & 2 & 3 & 4 & 5 & 6 & 7 & 8 & 9 & 10\end{array}$

Fonte: Entrevistas realizadas com os dez coordenadores regionais dos CGRs no estado do Rio de Janeiro.

Nessas oficinas foram conformados os Grupos Operacionais Provisórios, considerados embriōes dos CGRs. A fim de subsidiar as discussões, a SES reuniu uma série de informações relativas à oferta e produção de serviços da atenção básica, média e alta complexidade (RIO DE JANEIRO, 2009b). Adicionalmente, analisaram-se os fluxos migratórios das internações e procedimentos ambulatoriais entre municípios e regiōes. Nesse processo, além da problematização da situação 
de saúde de cada região, definiram-se as responsabilidades de cada esfera de governo e discutiu-se a possibilidade de conformação de novos arranjos e recortes regionais. As oficinas resultaram na conformação de nove CGRs.

Outros incentivos contribuíram para a implantação dos CGRs no estado, entre eles: a definição de espaço físico próprio, vinculado às estruturas regionalizadas previamente existentes (Centrais de Regulação e Núcleos de Vigilância em Saúde), a alocação de profissionais para organização administrativa do CGR (coordenador regional e secretário executivo) e de recursos financeiros federais e estaduais para aquisição de equipamentos e insumos.

Ainda em 2009, foram realizados Seminários de Planejamento Regional que envolveram a participação de Secretários Municipais de Saúde, representantes do nível central da SES, dos CGRs e do Conselho Estadual de Saúde. Como produto desses encontros, cada região desenvolveu um plano de ação específico para o enfrentamento de problemas regionais. Os CGRs foram considerados estratégicos nesse processo, no entanto os Planos Regionais não avançaram em suas propostas e não foram acompanhados a contento ao longo do tempo.

\section{Institucionalidade dos CGRs}

Observou-se que a elaboração de critérios vinculados à organização da atenção à saúde e otimização dos recursos disponíveis, assim como o histórico das relaçôes e os acordos políticos entre os municípios, condicionaram a definição inicial dos recortes regionais para implantação dos CGRs. Entretanto, interesses e projetos econômicos relacionados ao desenvolvimento regional tenderam a ser tratados de modo isolado, não tendo sido incorporados adequadamente no processo de regionalização da saúde.

Por outro lado, o próprio funcionamento dos CGRs gerou a necessidade de revisão dos acordos estabelecidos no momento inicial de sua implantação. Poucos meses após o início regular das reuniōes do CGR da Metropolitana I, representantes da Secretaria Municipal de Saúde da Capital e da SES propuseram a constituição de uma região distinta (RIO DE JANEIRO, 2009c). Alguns motivos foram mencionados para o desmembramento da região, dentre eles a autossuficiência de serviços de saúde e as características específicas da capital, e as expectativas de fortalecimento do caráter simétrico das relações intergovernamentais envolvendo os municípios da Baixada Fluminense. 
A despeito de tais argumentos, destaca-se que, historicamente, o espaço territorial atualmente denominado município do Rio de Janeiro sempre esteve desarticulado do restante do território fluminense. Após um longo período como capital nacional e, posteriormente, como estado da Guanabara, esse território teve dificuldades de se integrar e se identificar como Capital do estado do Rio de Janeiro. Posteriormente, retomou-se a conformação original dos CGRs, após um período de negociações entre o município do Rio de Janeiro, os municípios da Região Metropolitana I, a SES e o Ministério da Saúde (RIO DE JANEIRO, 2011).

Do ponto de vista organizativo, no período de 2009 a 2011, os CGRs eram compostos por Plenárias, Câmaras Técnicas e Grupos de Trabalho. As Plenárias e Câmaras Técnicas geralmente aconteciam uma vez ao mês. As Plenárias, tanto ordinárias quanto extraordinárias, eram compostas pela totalidade de secretários municipais de Saúde e coordenadas por um representante do nível central do estado. Para terem caráter deliberativo, deveriam apresentar quórum de maioria absoluta (presença de metade dos representantes da região mais um). A presença do representante do Nível Central do estado ou do coordenador regional também se fazia necessária para garantir o caráter deliberativo da reunião.

Entretanto, observaram-se variaçōes entre as regiōes no funcionamento dos CGRs. Essas variações estavam, muitas vezes, relacionadas às características mais específicas de cada região, e refletiam os condicionantes econômicos, sociais, culturais da região, ou ligadas à organização do sistema de saúde e à existência de práticas preexistentes de planejamento regional. Algumas regiōes no estado apresentavam dificuldades econômicas e eram mais frágeis em diversos aspectos como disponibilidade de profissionais qualificados, conhecimento dos processos relacionados à gestão da saúde e controle de seus próprios recursos. Não sem razão, essas regiões se encontravam em um estágio incipiente de funcionamento do CGR no momento da pesquisa e necessitavam de maior apoio da SES. Por outro lado, em regiōes onde havia maior disponibilidade de recursos financeiros e humanos ou nas quais já eram desenvolvidas práticas de planejamento regional e negociação intergovernamental, o funcionamento dos CGRs ocorria de maneira mais fluente.

Verificou-se que a atuação dos coordenadores regionais e da Secretaria Executiva foi um dos fatores centrais para o bom funcionamento dos CGRs. 
Eram estes os responsáveis por estabelecer um diálogo entre a SES e os municípios

e desenvolver um trabalho de organização das reuniōes e convocação dos participantes. As Câmaras Técnicas e Grupos de Trabalho também se mostraram importantes, sobretudo no que diz respeito ao suporte técnico para subsidiar as negociações e a tomada de decisão no CGR.

$\mathrm{Na}$ visão dos coordenadores regionais, dentre os fatores que dificultavam o funcionamento do CGR, foi mencionada a baixa regularidade da participação dos representantes municipais em algumas regiōes. Outro fator prejudicial ao funcionamento dos CGRs se refere às mudanças recorrentes de secretários municipais de Saúde, que comprometiam a continuidade de algumas ações. Além dos integrantes formais, outros atores participaram de modo eventual das reuniōes dos CGRs, tais como prestadores privados, conselheiros de saúde, membros de instituiçôes de ensino e pesquisa, e técnicos dos consórcios (gráfico 2). A participação desses atores foi justificada pela necessidade de informação sobre algum tema específico.

Gráfico 2. Participação de outros atores nas reuniões dos CGRs, além de seus integrantes formais, no período de 2009 a 2011, segundo percepção dos coordenadores regionais- Rio de Janeiro, 2011

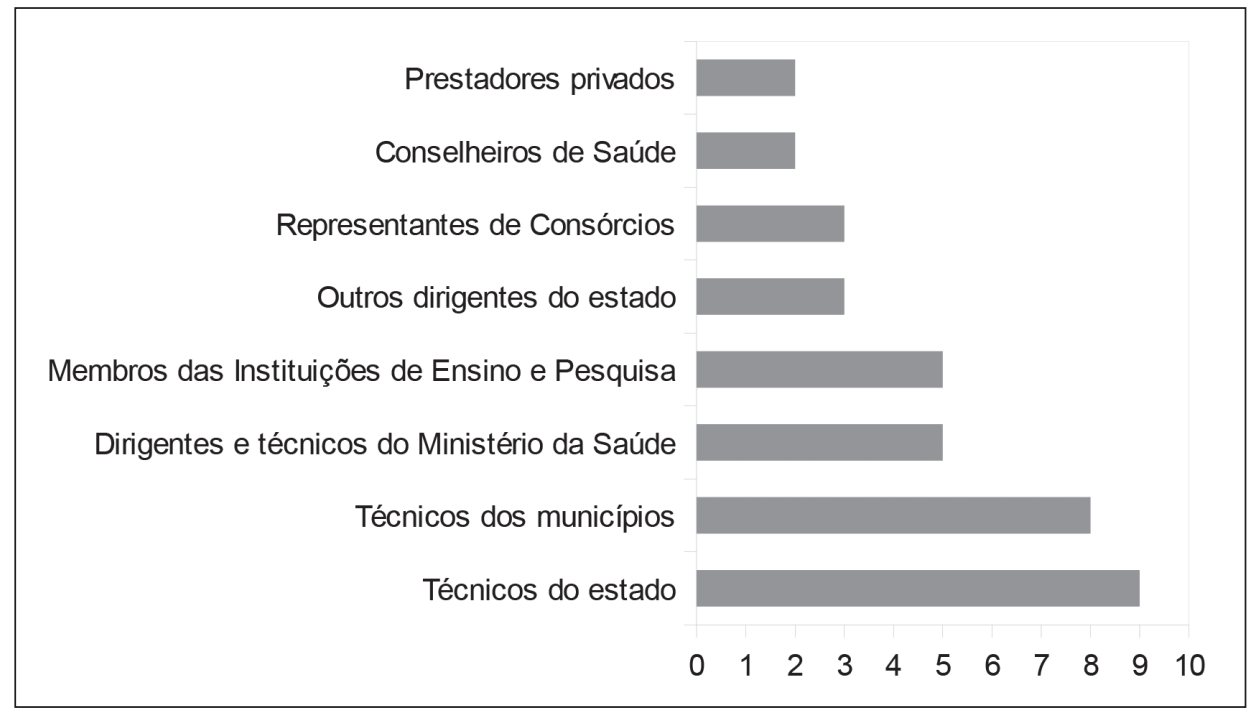

Fonte: Entrevistas realizadas com os dez coordenadores regionais dos CGRs no estado do Rio de Janeiro. 


\section{Processo político e padrões de relacionamento dos CGRs}

Entre os temas abordados nos CGRs, destacaram-se a Programação Pactuada Integrada (PPI) e a regulação da rede assistencial. Tais temáticas envolvem processos lentos de negociação entre os municípios e o estado, gerando necessidade de pactuação de recursos e definição de responsabilidades entre os gestores na região. $\mathrm{O}$ aspecto econômico-financeiro foi importante motivo de conflito nas reuniōes.

Uma temática pouco consensual entre estado e municípios envolveu a definição de responsabilidade em relação ao financiamento de leitos de Centros de Terapia Intensiva e de procedimentos de alto custo ou alta complexidade. Segundo os coordenadores regionais, os atores que exerceram maior influência sobre a definição da pauta dos CGRs foram os representantes da SES e os secretários municipais de Saúde. A construção dessa agenda sugere a constituição de um processo compartilhado, envolvendo os representantes municipais e estaduais. Destaca-se que o COSEMS participou em menor grau desse tipo de decisão.

As demandas e políticas específicas das regiōes prevaleceram na definição das pautas dos CGRs, seguida pelas demandas específicas dos municípios e demandas da SES (gráfico 3). O processo decisório nos CGRs foi influenciado predominantemente por instâncias e instituições governamentais, como a CIB, e as organizaçôes regionais da SES e COSEMS. O setor privado não teve destaque no que se refere à influência direta sobre as decisóes tomadas no âmbito dos CGRs.

A relação cooperativa e a convergência de visões e interesses prevaleceram nas reuniões e caracterizaram as relações município-município e estado-município. Porém, em menor grau, observou-se a existência de conflitos entre os municípios e cooptação na relação estado-municípios. ${ }^{1}$ Em algumas regiōes, os consórcios estabeleceram uma relação de complementaridade em relação ao CGR, mas também identificaram-se casos em que havia sobreposição de funções, particularmente quando o consórcio concorria com o CGR em seu papel de instância decisória em âmbito regional.

No que tange às estruturas de gestão regional da SES, como os Núcleos de Vigilância em Saúde (NDVS) e as Centrais Regionais de Regulação, prevaleceu uma relação de complementaridade em relação ao CGR. Essas organizaçooes regionais da SES, particularmente os NDVS, atuavam como parceiros e ofereciam suporte técnico aos CGRs na área de Vigilância em Saúde. Os NDVS 
aparentemente também se beneficiavam com a atuação dos CGRs, os quais facilitavam, através da presença de todos os gestores da região e do estado nas reuniōes, a supervisão e pactuação de indicadores ligados à Vigilância em Saúde.

Destaca-se a importância de redefinir papel e funções da CIB a partir da instituição dos CGRs. No estado do Rio de Janeiro, acordou-se que as temáticas de natureza regional deveriam ser conduzidas prioritariamente nos CGRs e posteriormente seriam encaminhadas para a CIB. Inversamente, informes, orientaçôes e decisões advindas da CIB passariam a definir a organização e o funcionamento dos CGRs, e ocupar suas pautas de discussão.

Verificou-se que a atuação do CGR facilitou o processo de tomada de decisão na CIB, já que muitas discussōes encaminhadas para esta instância de negociação passaram previamente por uma apreciação e pactuação no CGR, ampliando a legitimidade das decisôes da CIB. Ressalta-se, ainda, um aumento de temáticas regionais na pauta de discussão da CIB.

Gráfico 3. Fatores que influenciaram a pauta de discussão dos CGRs no período de 2009 a 2011 segundo percepção dos Coordenadores Regionais- Rio de Janeiro, 2011

Demandas dos profissionais de saúde

Demandas dos prestadores privados de serviços

Demandas do Conselhos de Saúde

Políticas específicas e demandas da SES

Demandas específicas dos municípios

Políticas específicas e demandas da região

$\begin{array}{lllllllllll}0 & 1 & 2 & 3 & 4 & 5 & 6 & 7 & 8 & 9 & 10\end{array}$

Fonte: Entrevistas realizadas com os dez coordenadores regionais dos CGRs no estado do Rio de Janeiro. 


\section{Capacidade de atuação dos CGRs: planejamento regional e gestão intergovernamental}

A principal função dos CGRs relacionava-se à definiç̧ão dos fluxos de referência intermunicipais e à organização da rede assistencial, com vistas a favorecer o acesso às ações e serviços de saúde. Ainda que as principais funções do CGR enfatizassem a organização da rede assistencial, havia a compreensão de que essa instância poderia favorecer a elucidação e o reconhecimento do espaço regional pelos gestores, contribuir para a construção de políticas adequadas às distintas realidades regionais e sinalizar para a SES as prioridades e rumos a serem tomados.

Não obstante, no estado do Rio de Janeiro, as principais discussões nos CGRs se concentraram prioritariamente em temas como definição de referências intermunicipais, Programação Pactuada Integrada da Assistência e Regulação da rede assistencial. Nesse contexto, o planejamento regional, incluindo a elaboração de um diagnóstico, definição de prioridades, metas, responsabilidades e recursos necessários, não recebeu tanto destaque.

Observaram-se, no entanto, iniciativas voltadas para a elaboração, no âmbito das regióes, de planos específicos relativos às políticas nacionais. Dessa forma, o CGR também se caracterizou como um instrumento de coordenação de políticas mais amplas propostas pela esfera nacional e estadual, já que estas definem a negociação intergovernamental e a elaboração de planos regionais como prérequisitos para sua implantação e repasse de recursos financeiros. Tais políticas federais influenciaram a negociação regional e a organização da rede de atenção à saúde no caso do Rio de Janeiro. Por outro lado, não se verificou, no período de estudo, uma atuação mais autônoma do CGR em relação à definição de projetos regionais que considerassem as especificidades do estado.

Ainda que tais práticas de planejamento não estivessem absolutamente desenvolvidas, esse era um processo que estava em construção e dependia do estabelecimento de uma cultura que permitisse atuação mais sistêmica na identificação e solução de problemas, em oposição a uma atuação mais isolada dos municípios. Segundo relato de um dos representantes do COSEMS:

Os municípios, ao longo dos anos, até mesmo pelo modelo de descentralização adotado, levantaram uma fronteira entre eles, e o CGR está colaborando para um estreitamento das relações entre esses municípios. 
Os CGRs, dessa forma, promoveram a aproximação entre os gestores municipais, apesar de já existirem, anteriormente à implantação dessas instâncias, outros mecanismos voltados para articulação e viabilização de uma ação mais integrada entre os municípios. A despeito do valor dessas experiências anteriores para a organização regional, nem sempre esses espaços de negociação intergovernamental funcionavam em todas as regióes de forma regular e contavam com estruturas técnico-políticas e administrativas formalizadas.

Outro avanço obtido através do CGR se relacionou a sua capacidade de promover o aprendizado em relação às bases legais e técnicas que fundamentam a política pública de saúde. De acordo com representantes do COSEMS, muitos municípios ainda necessitavam desenvolver e aprimorar suas capacidades técnicas, particularmente no que tange às políticas de saúde, regras de funcionamento do SUS e responsabilidades e atribuições de cada esfera de governo. Os CGRs, através das reuniōes ordinárias e Câmaras Técnicas, permitiam a troca de experiências e conhecimentos entre os participantes, contribuindo para que os gestores e técnicos dominassem com maior propriedade as políticas públicas de saúde.

Ainda que tenha sido identificada essa capacidade do CGR de promover o aprendizado técnico, através das trocas de conhecimento, destacou-se a necessidade de avançar em termos de reconhecimento dos papéis e responsabilidades desempenhados por cada ente. Verificaram-se, em relação a esse aspecto, impasses na definição das responsabilidades desempenhadas pelos municípios. Apesar de essa questão ter sido destacada como uma dificuldade para a organização regional, observou-se que os CGRs podem contribuir para um maior entendimento sobre as competências dos entes na política de regionalização e para que os secretários municipais de Saúde se reconheçam como representantes de determinada região.

\section{Discussão}

A implantação dos CGRs ocorreu tardiamente no estado do Rio de Janeiro. No ano de 2008, quase todos os estados já haviam constituído essas instâncias regionais, com exceção do Rio de Janeiro e de alguns estados na região Norte e Nordeste (LIMA et al., 2012).

A conformação tardia dos CGRs acompanha a própria trajetória da regionalização no estado do Rio de Janeiro, de início mais recente em comparação 
a outros estados (ALBUQUERQUE; MELLO; IOZZI, 2011), bem como o legado de políticas prévias de descentralização que enfatizaram a transferência de responsabilidades, funções e serviços para os municípios, sem revisão adequada do papel a ser desempenhado pela Secretaria de Estado de Saúde nesse processo.

É possível verificar na formação histórica desse estado fatores que dificultaram a constituição de processos de integração regional no campo da saúde. A separação entre dois entes governamentais distintos, o estado do Rio de Janeiro e o Estado da Guanabara, repercutiu no desenvolvimento econômico e social do território fluminense. Os investimentos públicos e privados foram centralizados no Estado da Guanabara, anteriormente Capital Federal, gerando grande adensamento populacional na região metropolitana. Em contrapartida, o desenvolvimento econômico do interior do estado não foi priorizado a contento e também não foram colocadas em prática estratégias que viabilizassem maior coordenação entre esses dois estados capazes de integrar o núcleo e a periferia e superar a fragmentação originada da divisão político-administrativa da região fluminense (NATAL, 2005). Esse processo de desenvolvimento econômico gerou desigualdades territoriais e assimetrias entre os municípios em relação à capacidade de assumir suas competências e responsabilidades na condução da política de saúde.

Destaca-se, ainda, que a descentralização nesse estado foi marcada por um enfoque predominantemente municipalista, sem considerar iniciativas voltadas para a regionalização da saúde. Por outro lado, verifica-se que o estado do Rio de Janeiro não chegou a se habilitar às condições de gestão mais avançada da Norma Operacional Básica SUS 01/96, o que reduziu ainda mais seu poder de coordenação da política de saúde no âmbito estadual, já que este não se beneficiou do aprendizado institucional vinculado aos dispositivos normativos federais e às transferências diretas de recursos do fundo nacional de saúde (NORONHA; MACHADO; LIMA, 2003). Dessa forma, além da assimetria de condições institucionais e financeiras entre os municípios, o processo de descentralização de corte eminentemente municipalista, a habilitação estadual tardia e a baixa capacidade de indução financeira do estado sugerem as dificuldades da SES em desempenhar um papel de coordenação do SUS e implementar a política de regionalização no estado.

Mais recentemente, no contexto do Pacto pela Saúde, a regionalização voltou a ocupar papel prioritário nas políticas de saúde desenvolvidas no estado. Embora 
o Pacto pela Saúde seja uma política federal, o contexto particular do estado do

Rio de Janeiro imprimiu características próprias à implementação das propostas e instrumentos referentes à regionalização. Iniciou-se, portanto, um novo processo decisório, com atores e estratégias específicos, que reformularam e direcionaram a política a partir da realidade estadual e regional. O quadro-síntese (quadro 2) dos principais resultados da pesquisa expressa as principais características relacionadas à implantação dos CGRs no estado.

\section{Quadro 2. Quadro-síntese dos resultados}

\begin{tabular}{|c|c|}
\hline Dimensões & Detalhamento (elementos predominantes) \\
\hline \multirow{4}{*}{$\begin{array}{l}\text { Indução e } \\
\text { Implantação } \\
\text { Inicial do CGR }\end{array}$} & $\begin{array}{l}\text { Confluência de fatores técnicos, políticos e institucionais para } \\
\text { incorporação da regionalização na agenda estadual. }\end{array}$ \\
\hline & $\begin{array}{l}\text { Diversidade de fatores que influenciaram a implantação dos CGRs: } \\
\text { determinações federais, legados de políticas prévias, atuação dos dirigentes } \\
\text { do nível central da SES e do Cosems, questôes regionais. }\end{array}$ \\
\hline & $\begin{array}{l}\text { Importância das oficinas regionais como estratégia voltada para a } \\
\text { sensibilização dos gestores municipais na constituição dos CGRs. }\end{array}$ \\
\hline & $\begin{array}{l}\text { Protagonismo da SES em parceria com o COSEMS na conformação dos } \\
\text { CGRs. }\end{array}$ \\
\hline \multirow{8}{*}{$\begin{array}{l}\text { Institucionalidade } \\
\text { do CGR }\end{array}$} & $\begin{array}{l}\text { Inicio tardio das atividades e funcionamento relativamente recente (a } \\
\text { partir de 2009). }\end{array}$ \\
\hline & $\begin{array}{l}\text { Atuação da SES nas funções de Coordenação Regional e Secretaria } \\
\text { Executiva. }\end{array}$ \\
\hline & Existência de único Regimento Interno para todos os CGRs. \\
\hline & $\begin{array}{l}\text { Presença de Câmaras Técnicas e Grupos de Trabalho para processamento } \\
\text { dos temas tratados em todos os CGRs. }\end{array}$ \\
\hline & $\begin{array}{l}\text { Variações no modo de operação dos CGRs e regularidade das plenárias } \\
\text { entre as regiões. }\end{array}$ \\
\hline & $\begin{array}{l}\text { Reconhecimento da baixa participação dos representantes municipais em } \\
\text { algumas regiōes. }\end{array}$ \\
\hline & $\begin{array}{l}\text { Participação eventual de técnicos da SES e de dirigentes do Ministério da } \\
\text { Saúde nas reuniões. }\end{array}$ \\
\hline & $\begin{array}{l}\text { Participação de prestadores privados, conselheiros de saúde e membros de } \\
\text { instituições de ensino e pesquisa condicionada à discussão de algum tema } \\
\text { específico. }\end{array}$ \\
\hline
\end{tabular}




\begin{tabular}{|c|c|}
\hline Dimensóes & Detalhamento (elementos predominantes) \\
\hline \multirow{6}{*}{$\begin{array}{l}\text { Processo político } \\
\text { e padrões de } \\
\text { relacionamento do } \\
\text { CGR }\end{array}$} & $\begin{array}{l}\text { Destaque da PPI e da Regulação da assistência como pontos de pauta nas } \\
\text { reuniōes dos CGRs. }\end{array}$ \\
\hline & $\begin{array}{l}\text { Diversidade da temática com ênfase nos aspectos relacionados à } \\
\text { Assistência à Saúde, Vigilância Epidemiológica e Formação e Gestão de } \\
\text { Recursos Humanos previstos nas políticas federais. }\end{array}$ \\
\hline & $\begin{array}{l}\text { Definição compartilhada das pautas dos CGRs (influência dos } \\
\text { representantes da SES e dos Secretários Municipais de Saúde), com } \\
\text { incorporação das demandas específicas das regiōes. }\end{array}$ \\
\hline & $\begin{array}{l}\text { Reconhecimento gradual dos CGRs como instâncias privilegiadas de } \\
\text { negociação e decisão no âmbito regional. }\end{array}$ \\
\hline & $\begin{array}{l}\text { Redefinição do papel de outras instâncias colegiadas do SUS após a } \\
\text { conformação dos CGRs. }\end{array}$ \\
\hline & Indefinição dos fluxos decisórios entre a CIB e os CGRs. \\
\hline \multirow{4}{*}{$\begin{array}{l}\text { Capacidade de } \\
\text { atuação do CGR }\end{array}$} & $\begin{array}{l}\text { Influência dos CGRs na organização da rede assistencial e definição de } \\
\text { fluxos de referência. }\end{array}$ \\
\hline & $\begin{array}{l}\text { Importantes expectativas dos gestores quanto ao papel dos CGRs na } \\
\text { construção de políticas adequadas às distintas realidades regionais }\end{array}$ \\
\hline & $\begin{array}{l}\text { Maior apropriação por parte dos gestores das políticas federais e estaduais } \\
\text { de saúde. }\end{array}$ \\
\hline & Maior participação dos gestores nos assuntos regionais. \\
\hline
\end{tabular}

Fonte: Elaboração própria.

Por meio do trabalho empírico, foram identificadas variações no funcionamento dos CGRs entre as regiōes. Foi ressaltado pelos gestores que as regiōes que já desenvolviam práticas de negociação intergovernamental e já possuíam estruturas regionais consolidadas na região, como consórcios e vice-presidências regionais do COSEMS, se encontravam em um estágio mais avançado de funcionamento do CGR. Nesses casos, a presença de estruturas regionais e práticas de planejamento instituídas anteriormente à conformação dos CGRs facilitou a constituição e o funcionamento dessas instâncias regionais, sugerindo que a institucionalidade desenvolvida em cada região influenciou os resultados dessa política.

Outro aspecto relevante diz respeito à necessidade, deflagrada após a conformação dos CGRs, de redefinir os papéis e atribuições de outras instâncias colegiadas e de gestão regional. Tal reorganização caracterizou-se por mudanças 
na atuação da CIB, através da pactuação de fluxos decisórios que definiam os CGRs como instância prioritária para tratar de temáticas regionais. Houve também interesse, principalmente por parte da SES, de limitar o papel político e decisório dos consórcios e de sua estrutura técnica e administrativa. Tais iniciativas sugerem uma valorização do CGR como instância privilegiada de negociação e decisão no âmbito regional.

Ainda que os CGRs tenham sido constituídos recentemente no estado e que existissem variações em seu funcionamento entre as regiões, foi possível verificar que essas instâncias favoreceram a discussão sobre a organização e regulação da assistência, através da definição e acompanhamento dos fluxos de referências. Esse aspecto é de grande relevância no que concerne à melhoria do acesso da população às ações e serviços que não são oferecidos nos limites territoriais do município. As discussões desenvolvidas nas reuniōes sugerem que é necessária uma estruturação mais consistente dos processos regulatórios, de forma a viabilizar o acesso oportuno e adequado de pacientes para os municípios de referência.

Percebeu-se, no entanto, a fragilidade do enfoque regional nas práticas relativas ao planejamento governamental. A ausência de projetos próprios às regiões reflete a trajetória da política de saúde no estado, que privilegiou o recorte municipal na definição de projetos e ações. Há também questões que ultrapassam o espaço de atuação dos CGRs, já que são dependentes do governo federal, tais como os instrumentos de financiamento, os quais nem sempre favorecem o fortalecimento de uma lógica regional para organizar o sistema de saúde. A esse respeito, Lima e Viana (2011) consideram que é necessário avançar na configuração de estratégias e instrumentos de planejamento, regulação e financiamento que possam apoiar a conformação de sistemas públicos de saúde regionais.

Apesar desse aspecto, os CGRs lograram elucidar questões relativas às políticas de saúde, por meio de trocas de experiências e conhecimentos entre gestores e técnicos, promovendo maior fundamentação para as negociações e discussões. Nesse ponto, vale ressaltar sua contribuição no reconhecimento das atribuições e competências dos entes governamentais em relação à política pública de saúde.

Os elementos apontados sugerem que os CGRs são inovações profícuas à política de saúde, embora ainda seja preciso avançar no que diz respeito ao desenvolvimento de uma cultura direcionada para o planejamento regional, que levem em consideração a região ponto de partida para a ação. Nesse processo, a função indutora e coordenadora atribuída à esfera estadual será de extrema importância. ${ }^{2}$ 


\section{Referências}

ALBUQUERQUE, M.V.; MELLO, G.A.; IOZZI, F.L. O processo de regionalização em saúde nos estados brasileiros. In: VIANA, A.L.D.; LIMA, L.D. (Org.). Regionalização e relaçôes federativas na política de saúde do Brasil. Rio de Janeiro: Contra Capa, 2011. p.117-173.

BARDIN, Laurence. Análise de Conteúdo. Lisboa: Ediçōes 70, 2010

BRASIL. Ministério da Saúde. Secretaria Executiva. Departamento de Apoio à Descentralização. Coordenação de Integração Programática. Colegiado de gestão regional na regiāo de saúde intraestadual: orientações para organização e funcionamento. Brasília: MS, 2009. (Série Pactos pela Saúde).

BRASIL. Portaria GM/MS no 1863, de 29 de setembro de 2003. Institui a Política Nacional de Atenção às Urgências, a ser implantada em todas as unidades federadas, respeitadas as competências das três esferas de gestão. Diário Oficial [da] República Federativa do Brasil, Brasília, DF, 2003.

BRASIL. Portaria GM/MS no 1.996, de 20 de agosto de 2007. Dispõe sobre a Política Nacional de Educação Permanente em Saúde. Diário Oficial [da] República Federativa do Brasil, Brasília, DF, 2007.

DAVIDOVICH, F. Estado do Rio de Janeiro: singularidade de um contexto territorial. Revista Território, n. 9, p. 9-24, 2000.

GERSCHMAN, S. Formulação e implementação de políticas de saúde no estado do Rio de Janeiro. In: UGÁ, M.A. et al. (Org.). A gestão do SUS no âmbito estadual. Rio de Janeiro: Fiocruz, 2010. p. 69-88.

HALL, P.A.; TAYLOR, R.C.R. As três versões do neoinstitucionalismo. Lua Nova, São Paulo, n. 58, p. 193-223, 2003.

HAM, C.; HILL, M. The policy process in the modern capitalist satã. Hertfordshire: Haverster Wheatsheaf, 1993.

HOWletT, M.; RAMESH, M. Studying Public Policy. New York: Oxford University Press, 1995.

LESSA, C. O Rio de todos os Brasis. Rio de Janeiro: Record, 2005.

LEVCOVITZ, E.; LIMA, L.D.; MACHADO, C.V. Política de saúde nos anos 90: relações intergovernamentais e o papel das Normas Operacionais Básicas. Ciência \& Saúde Coletiva. Rio de Janeiro, v. 6, n. 2, p. 269-291, 2001.

LIMA, A.P.G. de. Os Consórcios Intermunicipais de Saúde e o Sistema Único de Saúde. Cadernos de Saúde Pública, Rio de Janeiro, v. 16, n. 4, p. 985-996, 2000.

LIMA, L.D. O processo de implantação de novas estruturas gestoras no Sistema Único de Saúde: um estudo das relações intergovernamentais na CIB do RJ. Dissertação (Mestrado em Saúde Coletiva) - Instituto de Medicina Social, Universidade do Estado do Rio de Janeiro Rio de Janeiro, Rio de Janeiro, 1999. 
LIMA, L.D. et al. Descentralização e regionalização: dinâmica e condicionantes da implantação do Pacto pela Saúde no Brasil. Ciência \& Saúde Coletiva. Rio de Janeiro, v. 17, n. 7, p. 1903-1914, 2012.

LIMA, L.D.; VIANA, A.L.D. Descentralização, regionalização e instâncias intergovernamentais no Sistema Único de Saúde. In: VIANA, A.L.D.; LIMA, L.D. (Org.). Regionalização e relaçôes federativas na política de saúde do Brasil. Rio de Janeiro: Contra Capa, 2011. p. 39-67.

LUCCHESE, P.T.R. Descentralização do financiamento e gestão da assistência à saúde no Brasil: a implementação do Sistema Único de Saúde - retrospectiva 1990/1995. Planejamento e Políticas Públicas, v. XIV, p. 75-156, 1996.

MACHADO, C.V.; VIANA, A.L.D. Descentralização e coordenação federativa: a experiência brasileira na saúde. Ciência \& Saúde Coletiva, v. 14, n. 3, p. 807-817, 2009.

MINAYO, M.C.S. O desafio do conhecimento: pesquisa qualitativa em saúde. São Paulo: Hucitec, 2006.

MIRANDA, A.S. Processo decisório em Comissões Intergestores do Sistema Único de Saúde: governabilidade resiliente, integração sistêmica (auto) regulada. Revista de Política, Planejamento e Gestão em Saúde, v. 1, n. 1, p. 117-139, 2010.

NATAL, J. O Estado do Rio de Janeiro Pós-1995: dinâmica econômica, rede urbana e questão social. Rio de Janeiro: Pubblicati; 2005.

NORONHA, J.C.; LIMA, L.D.; MACHADO, C.V. O Sistema Único de Saúde. In: GIOVANELlA, L. et al. (Org.). Politicas e sistemas de saúde no Brasil. 2ed. Rio de Janeiro: Fiocruz, 2012. p.365-393.

NORONHA, J.C.; MACHADO, C.V.; LIMA, L.D. A metrópole Rio de Janeiro: desafios para o planejamento em saúde. In: NETO, E.R.; BÓGUS, C.M. Saúde nos aglomerados urbanos: uma visão integrada. Brasília: OPAS, 2003 (série técnica Projeto de Desenvolvimento de Sistemas e Serviços de Saúde).

PARADA, R.A. Construção do sistema estadual de saúde: antecedentes e formas de inserção. Physis: Revista de Saúde Coletiva,v. 1, n. 1, p. 19-104, 2001.

QUEIROZ, L.G. Arquitetura da cooperação intergovernamental: os consórcios em saúde pública em Mato Grosso. Dissertação (Mestrado em Saúde Pública) - Escola Nacional de Saúde Pública Sérgio Arouca, Fiocruz, Rio de Janeiro, 2001.

RIBEIRO, J.M. Conselhos de Saúde, comissões intergestores e grupos de interesse no Sistema Único de Saúde (SUS). Cadernos de Saúde Pública, v. 13, n. 1, p. 81-92, 1997.

RIO DE JANEIRO (Estado). Deliberação CIB-RJ ño.648, de 05 de maio de 2009. Constitui os Colegiados de Gestão Regional no Estado do Rio de Janeiro, Rio de Janeiro, 2009a. RIO DE JANEIRO (Estado). Deliberação CIB-RJ no 753, de 13 de novembro de 2009. Aprova nova Região de Saúde composta pelo município do Rio de Janeiro. Rio de Janeiro, 2009c. 
RIO DE JANEIRO (Estado). Deliberação CIB-RJ no 1.383, de 18 de agosto de 2011. Aprova o retorno da Capital para a Região Metropolitana I. Rio de Janeiro, 2011.

RIO DE JANEIRO (Estado). Secretaria Estadual de Saúde. Plano Estadual de Saúde do Rio de Janeiro 2008-2011. Rio de Janeiro: SES, 2008.

RIO DE JANEIRO (Estado). Secretaria Estadual de Saúde. Saúde na área: regionalização. Rio de Janeiro: SES, 2009b.

SCHNEIDER, A.C. Os consórcios intermunicipais de saúde no estado do Rio de Janeiro. Physis Revista de Saúde Coletiva. Rio de Janeiro, v. 11, n. 2, p. 51-66, 2001.

SILVA, I.F.; LABRA, M.E. As instâncias colegiadas do SUS no Estado do Rio de Janeiro e o processo decisório. Cadernos de Saúde Pública. Rio de Janeiro, v. 17, n. 1, p. 161-170, 2001.

THELEN, K.; STEINMO, S. Historical Institutionalism in Comparative Politics. In: THELEN, K.; LONGSTRETH, F.; STEINMO, S. (Org.). Historical institutionalism in comparative politics. New York: Cambridge University Press, 1992.

VIANA, A.L.D. et al. Novas perspectivas para a regionalização da saúde. São Paulo em Perspectiva, São Paulo, v. 22, n. 1, p. 92-106, 2008.

VIANA, A.L.D.; LIMA, L.D.; FERREIRA, M.P. Condicionantes estruturais da regionalização na saúde: tipologia dos Colegiados de Gestão Regional. Ciência \& Saúde Coletiva. Rio de Janeiro, v. 15, n. 5, p. 2317-2326, 2010.

VIANA, A.L.D.; BAPTISTA, T.W.F. Análise de Políticas de Saúde. In: GIOVANELLA, L. et al. (Org.). Políticas e sistemas de saúde no Brasil. Rio de Janeiro: Fiocruz, 2008. p.6-105.

YIN, R. K. Estudo de caso: planejamento e métodos. Porto Alegre: Bookman, 2001.

\section{Agradecimentos}

A pesquisa contou com recursos financeiros da Fundação Carlos Chagas de Amparo à Pesquisa do Estado do Rio de Janeiro (FAPERJ), no âmbito do Programa Jovem Cientista do Nosso Estado. Agradecemos à Secretaria de Estado de Saúde e ao Conselho de Secretarias Municipais de Saúde do Rio de Janeiro, pela disponibilidade em participar das entrevistas realizadas nesta pesquisa.

\section{Notas}

\footnotetext{
${ }^{1}$ As relações conflitivas caracterizam-se pelo predomínio de divergências e dificuldades para obtenção de consenso, enquanto as relações cooperativas são marcadas pela busca de consenso por meio da negociação e de parcerias. Por sua vez, a cooptação é caracterizada pelo predomínio de estratégias para adesão de propostas, mantendo-se sua formulação original.

${ }^{2}$ R. P. Vianna e L. D. Lima participaram igualmente da concepção e delineamento da pesquisa, interpretação dos dados, redação e aprovação da versão final do artigo.
} 
Regional Management Boards (CGR): actors, strategies and intergovernmental negotiations

The study analyzed the conformation of the Regional Management Boards (CGRs) in the state of Rio de Janeiro, in the context of the Health Pact, based on four key dimensions: induction and initial deployment, institution, political process and relationship patterns (intergovernmental and between joint management organisms) and capacity for action of CGRs. The main actors involved and the strategies used in the deployment process and the dynamics of the operation and content of negotiations in these regional bodies were identified. The deployment of CGRs was late in Rio de Janeiro as compared with other Brazilian states, following, however, the pattern of development of regionalization policies in the state. It was noticed that the functioning of these bodies and intergovernmental negotiation pact showed variations between regions, mainly related to preexisting planning practices, structures and mechanisms for regional co-management. Regarding the potential and challenges of CGRs, it was observed that although recently established, these instances succeeded in promoting greater integration between government agencies in regional areas. Moreover, they favored the exchange of experience and learning among managers, particularly in relation to public health policies. However, empirical work suggests that it is still necessary to move forward with regard to the development of a culture of regional planning, which allows greater autonomy for regions in developing policies adjusted to their own realities. In this process, the inducing and coordinating function assigned to the state level will be of utmost importance.

> Key words: Regionalization; intergovernmental relations; Regional Management Board. 